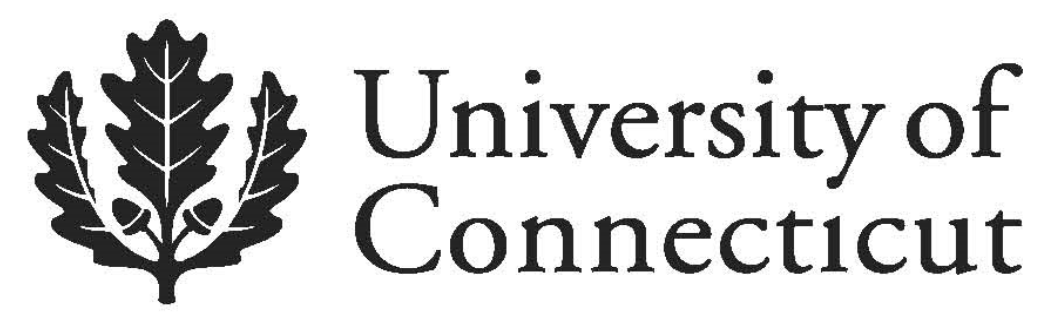

Department of Economics Working Paper Series

\title{
Products Liability When Consumers Vary in Their Susceptibility to Harm and May Misperceive Risk
}

Thomas J. Miceli

University of Connecticut

Kathleen Segerson

University of Connecticut

Suo Wang

University of Connecticut

Working Paper 2013-15

July 2013

365 Fairfield Way, Unit 1063

Storrs, CT 06269-1063

Phone: (860) 486-3022

Fax: (860) 486-4463

http://www.econ.uconn.edu/

This working paper is indexed on RePEc, http://repec.org 


\title{
Products Liability When Consumers Vary in Their Susceptibility to Harm and May Misperceive Risk
}

\author{
by \\ Thomas J. Miceli,* Kathleen Segerson,** and Suo Wang †
}

Abstract: This paper examines products liability when consumers have private information about their susceptibilities to product-related harm. In this case, it is efficient for consumers to selfselect in their purchases, with those especially prone to harm refraining from purchase.

Achieving this outcome requires consumers to bear their own harm, given that producers cannot observe consumer types. When consumers also misperceive risk, the problem becomes more complicated because accurate signaling of risk requires that firms bear liability. A trade-off therefore emerges between imposing liability on firms versus consumers. This paper characterizes the choice among liability rules in the presence of this trade-off.

Key words: Products liability, negligence, strict liability, consumer misperceptions JEL codes: K13, L15

July 2013

*Professor, Department of Economics, University of Connecticut, 365 Fairfield Way, Storrs, CT 06269; Ph: (860) 486-5810; Fax: (860) 486-4463; e-mail: Thomas.miceli@uconn.edu.

** Professor, Department of Economics, University of Connecticut, 365 Fairfield Way, Storrs, CT 06269; Ph: (860) 486-4567; Fax: (860) 486-4463; e-mail: Kathleen.segerson@uconn.edu

$\dagger$ Graduate student, ... 


\section{Products Liability When Consumers Vary in Their Susceptibility to Harm and May Misperceive Risk}

\section{Introduction}

A large literature has developed to explore the unique aspects of accidents involving consumer products when the victim is also the purchaser. ${ }^{1}$ The main difference between these product-related accidents and accidents in which the injurer and victim are "strangers" is that the amount consumers are willing to pay for a risky product will reflect the amount of harm they expect to incur in the event of an accident. This expectation will depend on two factors: the applicable liability rule for assigning accident damages, and the accuracy of consumers' perception of the risk of an accident. Two results are well-known in this context. First, when consumers correctly perceive the risk of a product-related accident, the outcome will be efficient regardless of the liability rule. This is essentially a consequence of the Coase Theorem (Coase, 1960), given that any assignment of liability imposed by the law will be perfectly reflected by an appropriate shift in the demand curve for the product. As a result, firms will choose optimal product safety, and consumers will purchase the efficient amount of the product. Second, when consumers misperceive risk, only strict liability is efficient because firms (which are assumed to perceive risks accurately) will set a price that correctly conveys product risk to consumers, so they will purchase the correct amount, and firms, because they bear the full damages from any accidents, will invest in efficient safety.

The current paper extends this literature by considering situations where consumers have private information, prior to purchase, about their differing susceptibilities to product-related harm. This is descriptive of many types of potentially harmful products, such as when

\footnotetext{
${ }^{1}$ See, for example, Oi (1973), Hamada (1976), Spence (1977), Shavell (1980), Landes and Posner (1985), Daughety and Reinganum (1997), and Spier (2011). For recent surveys, see Polinsky and Shavell (2010) (non-technical), and Daughety and Reinganum (forthcoming) (technical).
} 
consumers may have allergies to certain foods, when they may suffer side effects from certain drugs, or even when they differ in their physical abilities to use certain inherently dangerous products (like chain saws). In all of these cases, it is efficient for consumers to self-select in their purchases decisions, with those who are especially prone to harm refraining from purchase. A crucial factor in achieving this outcome, however, is that consumers must expect to bear their own harm, given that producers cannot identify consumer types prior to purchase. Thus, even with accurate consumer perceptions, the various liability rules are no longer equally efficient. (In particular, strict liability no longer leads to efficient purchase decisions.) When consumers also misperceive risk, the problem becomes more complicated because, while efficient selfselection requires consumers to bear their own harm, accurate signaling of risk requires that firms bear full liability. A trade-off therefore emerges between imposing liability on firms versus consumers. The purpose of this paper is to characterize the choice among the various liability rules (no liability, strict liability, and negligence) in the presence of this trade-off.

The general results can be summarized as follows. When all consumers suffer the same harm and perceive risk accurately, all of the liability rules are efficient, but when consumers misperceive risk, only strict liability remains efficient. When consumers suffer varying harm and perceive risk accurately, negligence and no liability are efficient, but strict liability is not. However, when consumers misperceive risk, none of the liability rules is efficient. In this case, the preferred rule depends on the degree of misperceptions: specifically, when consumers perceive risk fairly accurately, negligence is optimal, but when they perceive risk very inaccurately, strict liability is optimal.

The remainder of the paper is organized as follows. Section 2 lays out the model, and Section 3 examines the benchmark case where all consumers suffer the same harm. Section 4 
then turns to the case where harm varies across consumers and derives the main results. Finally, Section 5 summarizes the conclusions.

\section{The Model}

Consider a product the consumption of which creates the risk of harm to the consumer. ${ }^{2}$ Let $\pi(x)$ be the probability of an accident per unit of output, where $x$ is the manufacturer's spending on safety (or care) per unit, and $\pi^{\prime}<0, \pi^{\prime \prime}>0$. Risk is therefore decreasing at a decreasing rate in care. To account for the possibility of misperceptions, let $\lambda \pi(x)$ be the consumer's perceived risk, where $\lambda$ is an index of the degree of misperceptions. We focus on the case where consumers have identical misperceptions and possibly underestimate risk, or $\lambda \leq 1$.

We assume, however, that firms correctly perceive risk.

Additional notation is as follows:

$h=$ harm suffered by the victim in the event of an accident;

$a=$ gross value of the product to the consumer (i.e., the value of a safe product);

$c=$ constant marginal (=average) cost of production (other than safety features) per unit

of the product;

$P=$ price of the product.

The true expected value of a unit of the product is therefore $a-\pi(x) h$, while the total production cost per unit is $c+x$. Consumers purchase at most one unit of the product, and vary in their gross valuation, $a$, which we assume is distributed uniformly on $[0, \bar{a}]$, with distribution function $G(a)$ and density function $g(a)$, where $g^{\prime} \equiv 0$.

\footnotetext{
${ }^{2}$ Hay and Spier (2005) consider a model of product accidents in which the victim is a third party rather than the consumer.
} 
As a benchmark, we will consider the case where all consumers suffer the same harm, $h$, which is common knowledge. Then we will turn to the case where $h$ varies across consumers. In that setting, we will assume that consumers know their own $h$ prior to purchase, but that manufacturers only know the distribution function $F(h)$ and its associated density $f(h)$, both of which are defined on $[0, \bar{h}]$. For simplicity, we will assume that $a$ and $h$ are independently distributed, and that $\bar{a}$ is large enough relative to $h$ in the single-harm case, and to $\bar{h}$ in the varying-harm case, so that at least some consumers find it desirable to purchase the product. ${ }^{3}$

We consider the case of a perfectly competitive market to avoid complications arising from market power. ${ }^{4}$ Thus, following Hay and Spier (2005), we will assume that firms compete by choosing price, $P$, and product safety, $x$, to maximize consumer surplus (as perceived by consumers) subject to a non-negative profit constraint. In this setting, we consider three rules: no liability, strict liability, and negligence. We assume that the applicable rule is known by all parties, and that firms have sufficient resources to pay damages in the event that they face liability. Thus, we ignore judgment-proof problems. ${ }^{5}$ Finally, we assume that consumers can observe the level of product safety, $x$, at the time of purchase.

\section{Consumers Suffer the Same Harm}

\subsection{Social Optimum}

We first derive the socially optimal level of product safety, denoted $x *$, and the socially optimal amount of consumption. Given $x$, it is efficient for a consumer to purchase the product if and only if

\footnotetext{
${ }^{3}$ In the varying- $h$ case, we will more specifically assume (without loss of generality) that when consumers correctly perceive risk (i.e., when $\lambda=1$ ), at least some consumers at all levels of $h$ desire to purchase the product.

${ }^{4}$ For models of products liability that incorporate market power, see Epple and Raviv (1978), Polinsky and Rogerson (1983), and Marino (1988).

${ }^{5}$ See Shavell (1986) and Beard (1990).
} 


$$
a-\pi(x) h \geq c+x
$$

or if and only if

$$
a \geq c+x+\pi(x) h \equiv a^{*}(x)
$$

Given efficient purchase as defined by (1), the socially optimal level of safety maximizes the net benefit for those consumers who are in the market. This involves maximizing

$$
W(x)=\int_{c+x+\pi(x) h}^{\bar{a}}(a-c-x-\pi(x) h) g(a) d a .
$$

The resulting first order condition is

$$
1+\pi^{\prime}(x) h=0
$$

which defines $x^{*}$. Substituting $x^{*}$ into (1) defines optimal consumption.

\subsection{Outcome Under Various Liability Rules}

This section derives the equilibrium outcome under each of the three liability rules, taking account of the possibility of consumer misperceptions.

No liability. Under a rule of no liability (caveat emptor), consumers will bear their own harm, so given $P$ and $x$ they will purchase the product if and only if

$$
a \geq P+\lambda \pi(x) h
$$

Firms choose $x$ and $P$ to maximize the resulting expected consumer surplus (as perceived by consumers), which is given by

$$
S_{N L}(x, \lambda)=\int_{P+\lambda \pi(x) h}^{\bar{a}}(a-P-\lambda \pi(x) h) g(a) d a,
$$

subject to a non-negative profit constraint. Perfect competition ensures that in equilibrium this constraint will bind, i.e., $P=c+x$. Substituting this expression for $P$ into (5) and maximizing the resulting expression with respect to $x$ therefore yields the first order condition

$$
1+\lambda \pi^{\prime}(x) h=0
$$


Let $\hat{x}(\lambda)$ denote the solution to (6). Note that $\hat{x}(\lambda)$ depends on the degree of misperceptions but not on the distribution of consumer types. Differentiating (6) shows that $\partial \hat{x}(\lambda) / \partial \lambda>0$, which, given (3), implies that $\hat{x}(\lambda) \leq x^{*}$ as $\lambda \leq 1$. Thus, firms will underinvest in safety when consumers underestimate risk, and in the limit, when $\lambda=0$, they will set $x=0$. As for consumption, note that in equilibrium, $P=c+\hat{x}(\lambda)$ by the zero profit constraint. Substituting this into (4), and noting that $\hat{x}(\lambda)+\lambda \pi(\hat{x}(\lambda)) h \leq x^{*}+\pi\left(x^{*}\right) h$ for $\lambda \leq 1^{6}$ implies that consumers overconsume the product relative to (1) when $\lambda<1$. The conclusion is that if consumers correctly perceive risk, the outcome under no liability is efficient, but if they underestimate risk, they will overconsume the product and producers will underinvest in safety.

Strict liability. Under strict liability, the consumption condition is simply $a \geq P$, and the expression for consumer surplus is

$$
S_{S L}(x)=\int_{P}^{\bar{a}}(a-P) g(a) d a .
$$

Note, therefore, that in contrast to the situation under no liability, consumer perceptions do not affect their purchase decisions under strict liability. Zero profit in this case requires $P=c+x+\pi(x) h$. Using this expression to substitute for $P$ in (5), and maximizing with respect to $x$, yields (3). Thus, firms choose the efficient level of product safety. The resulting price is $P=c+x^{*}+\pi\left(x^{*}\right) h$, which also yields the efficient consumption decision. Thus, regardless of consumer perceptions, strict liability yields the efficient outcome. That is, $S_{S L}\left(x^{*}\right)=W\left(x^{*}\right)$.

Negligence. Finally, consider a negligence rule, which allows firms to avoid liability by meeting the due standard of safety. When consumers perceive risk accurately, the obvious choice for the due standard is $x^{*}$, the level of safety that solves (3). When $\lambda<1$, however, that standard will not be efficient. Rather, the efficient $x$ maximizes

\footnotetext{
${ }^{6}$ The inequality follows from the fact that $\hat{x}(\lambda)+\lambda \pi(\hat{x}(\lambda)) h$ is increasing in $\lambda$ by the Envelope Theorem, and $\hat{x}(1)=x^{*}$.
} 


$$
W_{\lambda}(x, \lambda)=\int_{c+x+\lambda \pi(x) h}^{\bar{a}}(a-c-x-\pi(x) h) g(a) d a,
$$

which is welfare based on the true risk but the actual consumption decisions by consumers, given their perceptions. Let $x *(\lambda)$ denote the level of safety that maximizes (8), where $x *(1) \equiv x *$ given that $W_{\lambda}(x, 1) \equiv W(x)$. The uniformity of $g(a)$ further allows us to prove that $\partial x^{*}(\lambda) / \partial \lambda<0$ for $\lambda<1,{ }^{7}$ which implies that when consumers underestimate risk, optimal safety should be raised above $x^{*}$. Intuitively, because consumers will tend to overconsume the product in this case, firms should respond by making it safer. To make the best possible case for negligence, we will adopt $x^{*}(\lambda)$ as the due standard. ${ }^{8}$ The rationale for this choice is that often firms that are aware of product risks will also be aware that those risks are not known (i.e., are underestimated) by consumers. By basing the due standard on the degree of misperception, courts would essentially be holding firms responsible for reasonable care, given their knowledge of risk perceptions. Such a standard would effectively prevent producers from profiting from their superior knowledge of the risk. (Below, we comment on the implications of adopting $x *$ as the due standard instead.)

Note that negligence is just a combination of no liability and strict liability, separated by the due standard. Thus, given the due standard of $x *(\lambda)$, firms will choose the level of safety to maximize

$$
S_{\text {Neg }}(x, \lambda)=\begin{array}{ll}
\int_{P+\lambda \pi(x) h}^{\bar{a}}(a-P-\lambda \pi(x) h) g(a) d a, \text { where } P=c+x, & x \geq x^{*}(\lambda) \\
\int_{P}^{\bar{a}}(a-P) g(a) d a, \text { where } P=c+x+\pi(x) h, & x<x^{*}(\lambda),
\end{array}
$$

\footnotetext{
${ }^{7}$ Specifically, $\partial^{2} W_{\lambda} / \partial x \partial \lambda=\pi(x) h(1-\lambda) g(\cdot) \pi^{\prime}(x)<0$. Note that if $g$ were not uniform, there would be a $g$ ' term in this expression, which would make the sign of the overall expression ambiguous because it would depend on the shape of the density function.

${ }^{8}$ The current model differs in this respect from Polinsky and Rogerson (1983), who set the due standard at $x^{*}$ regardless of consumer perceptions.
} 
where the top line coincides with (5) and the bottom line coincides with (7). Observe first that when $\lambda=1$, both lines are maximized at $x^{*}$, which is also the due standard, and so firms will always comply with the standard. Thus, when consumers perceive risk accurately, the negligence rule yields the efficient outcome.

When $\lambda<1$, however, firms may or may not find it optimal to comply with the due standard. The situation can be seen graphically in Figure 1, where the top and bottom lines in (9) are graphed as $S_{N L}(x, \lambda)$ and $S_{S L}(x)$, respectively. Note that $S_{N L}(x, \lambda)$ is drawn as everywhere above $S_{S L}(x)$. This is true because, although the two expressions coincide when $\lambda=1$, from (5)

$$
\frac{\partial S_{N L}(x, \lambda)}{\partial \lambda}=-\int_{P+\lambda \pi(x) h}^{\bar{a}} \pi(x) h g(a) d a<0,
$$

whereas $S_{S L}(x)$ is independent of $\lambda$. Thus, when $\lambda<1, S_{N L}(x)>S_{S L}(x, \lambda)$ for all $x$. Realized welfare, $W_{\lambda}(x, \lambda)$, is also graphed, where from $(8)$

$$
\frac{\partial W_{\lambda}(x, \lambda)}{\partial \lambda}=\pi(x)^{2} h^{2} g(\cdot)(1-\lambda)>0 .
$$

Thus, when $\lambda<1, W_{\lambda}(x, \lambda)$ is everywhere below $S_{S L}(x)$ given that $S_{S L}(x)=W_{\lambda}(x, 1)$.

For the case shown in Figure 1, expected consumer surplus is higher at point A, which is (perceived) consumer surplus when firms comply with the due standard, than it is at point B, which is consumer surplus when firms violate the due standard and are held liable. For $\lambda$ sufficiently close to one, this must be true. However, as $\lambda$ falls further below one, there are offsetting effects on the compliance decision. On one hand, the due standard increases given $\partial x^{*}(\lambda) / \partial \lambda<0$, which will make compliance less desirable because point A shifts rightward. On the other hand, $S_{N L}(x, \lambda)$ shifts upward given (10), which will make compliance more desirable because point A shifts up. Because of these offsetting effects, it is possible that for some values of $\lambda<1$, firms will find it optimal not to comply with $x *(\lambda)$. When that is the case, the outcome is identical to that under strict liability. In what follows, however, we focus on 
cases where firms find it optimal to meet the due standard, for otherwise, the negligence rule would have no effect.

[Figure 1 here]

Proposition 1: Assume that when consumers underestimate risk $(\lambda<1)$, the due standard under negligence is set at $x^{*}(\lambda)$, and firms find it optimal to comply. Then, strict liability is preferred to negligence, and negligence is preferred to no liability. ${ }^{9}$

If, following Polinsky and Rogerson (1983), we had set the due standard at $x *$ instead of $x *(\lambda)$, it should be clear from Figure 1 that firms would always comply with the standard because it would be independent of $\lambda$. (In particular, point A would be directly above point B.)

However, the efficiency of the outcome under negligence would correspondingly decline as $\lambda$ fell further below one (assuming compliance) because the equilibrium level of safety would deviate further from the (second-best) efficient level, $x^{*}(\lambda)$.

We conclude this section by summarizing the results for the single $h$ model:

Proposition 2: (a) When all consumers suffer the same damages from an accident and correctly perceive risk $(\lambda=1)$, all three liability rules—no liability, strict liability, and negligence-yield the efficient outcome. (b) When consumers underestimate risk $(\lambda<1)$, strict liability continues to be efficient, but negligence and no liability are not. However, negligence with due care set at $x *(\lambda)$ is more efficient than no liability.

The conclusion that only strict liability is efficient when consumers misperceive risk was previously shown by Spence (1977), Shavell (1980), Polinsky and Rogerson (1983), and Landes

\footnotetext{
${ }^{9}$ All proofs are contained in the Appendix.
} 
and Posner (1985). Shavell (1980) also demonstrated that, although both rules are inefficient, negligence is preferred to no liability in that case (where he also allows the due care level to be set at its second-best level). The next section extends this analysis to the case where consumers knowingly vary in their susceptibility to harm, which has not been previously studied.

\section{Consumers Vary in Their Susceptibility to Harm}

As discussed above, the case where consumers vary in their susceptibility to harm raises the question of self-selection by consumers regarding who should and should not consume the product based not only on their valuation of the product but also on their individual (and privately known) harm from a product-related accident. To capture this, we now assume that consumers know their own $h$ prior to purchase, but firms only know the distribution, $F(h)$.

\subsection{Social Optimum}

For any choice of $x$, optimal consumption of the good is determined by the inequality

$$
a \geq c+x+\pi(x) h \equiv a *(x, h)
$$

which is identical to (1) except that $h$ is now consumer-specific. Thus, (12) defines a region in $(a, h)$ space, as shown in Figure 2. It is therefore efficient for consumers with high $a$ and/or low $h$ to consume the product.

[Figure 2 here]

Because firms cannot observe and condition product safety on individual consumer harm levels, they must choose a single safety level. Thus, socially optimal care will involve a choice of $x$ that reflects the average harm of those consumers actually in the market. Specifically, given (12), $x *$ will maximize welfare:

$$
W(x)=\int_{0}^{\bar{h}} \int_{c+x+\pi(x) h}^{\bar{a}}(a-c-x-\pi(x) h) g(a) f(h) d a d h,
$$


which yields the first order condition

$$
\int_{0}^{\bar{h}} \int_{c+x+\pi(x) h}^{\bar{a}}\left(1+\pi^{\prime}(x) h\right) g(a) f(h) d a d h=0
$$

We now re-examine the outcome under the various liability rules when consumers vary in their susceptibility to harm.

\subsection{Outcome Under the Various Liability Rules}

No liability. Under no liability, the consumption region is defined by (4), but again this now represents a region in $(a, h)$ space bounded by the locus $\hat{a}(x, h, \lambda)=P+\lambda \pi(x) h$. Thus, the lower is $\lambda$, the flatter is the boundary of the consumption region (i.e., the more it tilts toward high- $h$ consumers). The level of consumer surplus as perceived by consumers is given by

$$
S_{N L}(x, \lambda)=\int_{0}^{\bar{h}} \int_{P+\lambda \pi(x) h}^{\bar{a}}(a-P-\lambda \pi(x) h) g(a) f(h) d a d h
$$

which firms maximize subject to $P=c+x$. As in the single- $h$ case, (15) coincides with social welfare in (16) when $\lambda=1$, but deviates when $\lambda<1$.

Substituting for $P$ in (15) and maximizing with respect to $x$ yields the first-order condition

$$
\int_{0}^{\bar{h}} \int_{c+x+\lambda \pi(x) h}^{\bar{a}}\left(1+\lambda \pi^{\prime}(x) h\right) g(a) f(h) d a d h=0,
$$

which is the analog to (6). Let $\hat{x}(\lambda)$ denote the solution to (16). Comparison of (16) and (14) shows that when $\lambda=1$ the outcome under no liability is efficient, but when $\lambda<1$, it is not. Totally differentiating (16) shows that $\partial \hat{x} / \partial \lambda>0$, implying that, as in the single- $h$ case, firms invest less in product safety as consumers' increasingly underestimate risk; that is, $\hat{x}(\lambda) \leq x^{*}$ as $\lambda \leq 1$. $^{10}$

Strict liability. Now consider strict liability. As above, the consumer's consumption condition is $a \geq P$, which is independent of $h$. Thus, in contrast to the case under no liability,

\footnotetext{
${ }^{10}$ Specifically, $\frac{\partial^{2} S_{N L}}{\partial x \partial \lambda}=-\int_{0}^{\bar{h}} \int_{c+x+\lambda \pi(x) h}^{\bar{a}} \pi^{\prime}(x) h g(\cdot) f(h) d h+\int_{0}^{\bar{h}}\left(1+\lambda \pi^{\prime}(x) h\right)^{2} g(\cdot) f(h) d h>0$, which, given $\frac{\partial^{2} S_{N L}}{\partial x^{2}}<0$ (by the second order condition), implies that $\frac{\partial \hat{x}}{\partial \lambda}>0$.
} 
consumers will not base their consumption decisions on their individual susceptibilities to harm or on their perceptions of risk. This is true because consumers expect to be fully compensated for any damages they incur and so base their purchase decisions solely on a comparison of their gross valuation and the price. As for producers, they cannot observe individual $h$ 's so they have to charge the same price for all consumers. As a result, no self-selection by consumer types will occur, implying that expected damages among consumers will be $E(h)$, the average harm in the population as a whole. Thus, in contrast to the single- $h$ case, the efficient outcome will not be attainable under strict liability, even though consumer perceptions do not matter.

Firms will specifically choose $x$ to maximize

$$
S_{S L}(x)=\int_{0}^{\bar{h}} \int_{P}^{\bar{a}}(a-P) g(a) f(h) d a d h,
$$

subject to $P=c+x+\pi(x) E(h)$. The resulting first order condition, which defines the level of safety under strict liability, is given by

$$
1+\pi^{\prime}(x) E(h)=0 .
$$

Let $x_{S L}$ denote the resulting level of safety.

Lemma: Given uniformity of $g(\cdot), x_{S L}>x^{*}$, or safety under strict liability is higher than the efficient level as defined by (14).

Intuitively, because self-selection by consumers based on their susceptibility to harm does not occur under strict liability, some high- $h$ consumers who would refrain from consumption of the good in the efficient outcome are willing to enter the market knowing that they will be fully compensated for their losses. As a result, the average harm in the market is 
higher under strict liability as compared to the efficient outcome, and so firms invest more in safety.

Negligence. As above, negligence is a combination of strict and no liability. In keeping with the single- $h$ case above, we set the due care standard at $x *(\lambda)$, the level of safety that maximizes welfare given the actual perceptions of consumers. Specifically, $x *(\lambda)$ maximizes

$$
W_{\lambda}(x, \lambda)=\int_{0}^{\bar{h}} \int_{c+x+\lambda \pi(x) h}^{\bar{a}}(a-c-x-\pi(x) h) g(a) f(h) d a d h .
$$

Given this due standard, firms choose $x$ to maximize

$$
\begin{aligned}
& \int_{0}^{\bar{h}} \int_{P+\lambda \pi(x) h}^{\bar{a}}(a-P-\lambda \pi(x) h) g(a) f(h) d a d h, \text { where } P=c+x, \quad x \geq x^{*}(\lambda) \\
& S_{\text {Neg }}(x, \lambda)= \\
& \int_{0}^{\bar{h}} \int_{P}^{\bar{a}}(a-P) g(a) f(h) d a d h, \text { where } P=c+x+\pi(x) E(h), \quad x<x *(\lambda),
\end{aligned}
$$

where the top line corresponds to $S_{N L}(x, \lambda)$ and is maximized at $\hat{x}(\lambda)$, while the bottom line corresponds to $S_{S L}(x)$ and is maximized at $x_{S L}$.

Consider first the situation when $\lambda=1$. In that case, the top line coincides with social welfare (i.e., $S_{N L}(x, 1)=W(x)$ ), and the due standard is the efficient level of care, $x^{*}$. As for the bottom line, it is possible to show that $S_{S L}(x)<W(x)$ for all $x$. Further, we saw above that $x_{S L}>x^{*}$. It follows that when $\lambda=1$, firms will always find it optimal to meet the due standard. This is true because the top line is maximized at $x^{*}$, while the bottom line is everywhere below the top line and is increasing at $x^{*}$. The result is shown graphically in Figure 3. Thus, as in the single- $h$ case, a negligence rule achieves the efficient outcome when consumers perceive risks accurately.

[Figure 3 here]

Now suppose that $\lambda<1$. Again, the top line in (20) is maximized at $\hat{x}(\lambda)$, while comparison of (15) and (19) shows that $S_{N L}(x, \lambda)>W_{\lambda}(x, \lambda)$ for all $x$ when $\lambda<1$. Also, since the due standard, $x^{*}(\lambda)$, is now larger than $x^{*}$ (given $\partial x^{*}(\lambda) / \partial \lambda<0$ ), it follows that $x^{*}(\lambda) \stackrel{\geq}{<} x_{S L}$. If $x^{*}(\lambda)$ is 
either less than, or not too much above, $x_{S L}$, then firms will find it optimal to comply with the due standard because that involves lower costs than would be possible under strict liability. However, if $x^{*}(\lambda)$ is substantially above $x_{S L}$, firms may find it profitable to violate the due standard because it is too stringent. As in the single- $h$ case above, however, we will focus only on situations where firms choose to meet the due standard. In that case, we have

Proposition 3: Assume that firms find it optimal to comply with the due standard under negligence. Then (a) when $\lambda=1$, no liability and negligence are efficient, but strict liability is not; (b) when $\lambda<1$, none of the rules is efficient, but negligence is more efficient than no liability.

It remains to compare negligence and strict liability when $\lambda<1$.

Proposition 4: Assume that firms find it optimal to comply with the due standard under negligence. Then there exists a critical value of $\lambda$, denoted $\lambda^{*} \in(0,1)$, such that negligence is preferred to strict liability when $\lambda>\lambda^{*}$, and strict liability is preferred to negligence when $\lambda<\lambda^{*}$.

[Figure 4 here]

The intuition for this result centers on the trade-off between efficient self-selection by consumers according to their susceptibility to harm on one hand, which requires them to face their own damages, and consumer misperceptions on the other, which potentially distort their consumption decisions. When perceptions are relatively accurate $(\lambda \rightarrow 1)$, negligence is the preferred rule because, given compliance by firms with the due standard, consumers bear their own harm and so self-select in their consumption decisions. Indeed, when $\lambda=1$, negligence achieves the efficient outcome whereas strict liability does not. However, when perceptions are 
very inaccurate $(\lambda \rightarrow 0)$, strict liability is preferred because, although no self-selection occurs, consumers at least receive an accurate signal of product risk through the price. ${ }^{11}$

\section{Summary of Results}

The overall results of this and the preceding section are summarized in Table 1, which defines four cases, depending on whether consumers accurately perceive the risk of an accident, and whether they vary in the resulting harm. As shown, when consumers perceive risk accurately and all suffer the same harm (the upper left box), all three liability rules—no liability, strict liability, and negligence-achieve the efficient outcome. When consumers misperceive risk but suffer the same harm (the upper right box), only strict liability remains efficient, but an appropriately structured negligence rule is preferred to no liability.

\section{[Table 1 here]}

When consumers vary in their susceptibility to harm and perceptions are accurate (lower left box), only no liability and negligence are efficient. Strict liability is not efficient in this case because it does not promote self-selection by consumers based on their individual-specific harm levels. Finally, when consumer misperceptions are added (lower right box), none of the rules is efficient, with the optimal rule (as between strict liability and negligence) depending on the degree of misperception. Specifically, when misperceptions are not too severe, negligence is preferred over strict liability because it promotes some amount of consumer self-selection, even though there is overconsumption as a result of consumer underestimation of risk. In contrast, when misperceptions are severe, strict liability is preferred; although no self-selection occurs, the price of the product at least sends an accurate signal of the average risk.

\footnotetext{
${ }^{11}$ A similar result is derived by Miceli, Rabon, and Segerson (forthcoming) in terms of the comparison between regulation and liability for controlling product risks.
} 
Based on these conclusions, the historical trend in products liability law toward strict liability over the past century is consistent with efficiency for those products where consumer harm is the same across consumers, either in actual or expected terms. When consumers knowingly differ in their susceptibility to harm, however, strict liability is only optimal if consumer misperceptions are severe, for in that case, it is more important to prevent excessive consumption across all consumers than to induce sorting by individual consumer types. Whether or not this is true, of course, will vary from product to product. However, as products have become increasingly complex, it seems plausible to suppose that consumers are becoming less and less able to accurately assess the risk, suggesting that the trend, at least, favors strict liability. 


\section{Appendix}

Proof of Proposition 1: As shown above, strict liability is efficient regardless of consumer perceptions, and yields welfare of

$$
W\left(x^{*}\right)=\int_{c+x^{*}+\pi\left(x^{*}\right) h}^{\bar{a}}\left(a-c-x^{*}-\pi\left(x^{*}\right) h\right) g(a) d a .
$$

As to the comparison between no liability and negligence, both are inefficient when $\lambda<1$, and yield welfare, respectively, of

$$
\begin{aligned}
& W_{\lambda}(\hat{x}(\lambda), \lambda)=\int_{c+\hat{x}(\lambda)+\lambda \pi(\hat{x}(\lambda)) h}^{\bar{a}}(a-c-\hat{x}(\lambda)-\pi(\hat{x}(\lambda)) h) g(a) d a \\
& W_{\lambda}\left(x^{*}(\lambda), \lambda\right)=\int_{c+x^{*}(\lambda)+\lambda \pi\left(x^{*}(\lambda)\right) h}^{\bar{a}}\left(a-c-x^{*}(\lambda)-\pi\left(x^{*}(\lambda)\right) h\right) g(a) d a .
\end{aligned}
$$

Given the uniformity of $g(a)$, we know that $\hat{x}(\lambda)<x^{*}<x^{*}(\lambda)$ for $\lambda<1$, where, recall, $x^{*}(\lambda)$ maximizes $W_{\lambda}(x, \lambda)$ for all $\lambda \leq 1$. It follows immediately that for $\lambda<1, W\left(x^{*}\right)>W_{\lambda}\left(x^{*}(\lambda), \lambda\right)>$ $W_{\lambda}(\hat{x}(\lambda), \lambda)$. This ranking is shown in Figure 1, where point B is realized welfare under strict liability, point $\mathrm{C}$ is realized welfare under negligence (given compliance), and point $\mathrm{D}$ is realized welfare under no liability.

Proof of lemma: Define the function

$$
S(x, \gamma)=\int_{0}^{\bar{h}} \int_{c+x+\pi(x)(\gamma h+(1-\gamma) E(h))}^{\bar{a}}(a-c-x-\pi(x) h) g(a) f(h) d a d h
$$

for some $\gamma \in[0,1]$, where $S(x, 0)=S_{S L}(x)$ and $S(x, 1)=W(x)$. Taking the derivative of this function with respect to $x$ and setting it equal to zero yields

$$
\begin{aligned}
& S_{x}=-\int_{0}^{\bar{h}} \int_{c+x+\pi(x)(\gamma h+(1-\gamma) E(h))}^{\bar{a}}\left(1+\pi^{\prime}(x) h\right) g(a) f(h) d a d h \\
& +\int_{0}^{\bar{h}}(1-\gamma) \pi(x)(h-E(h)) g(\cdot)\left(1+\pi^{\prime}(x)(\gamma h+(1-\gamma) E(h)) f(h) d h=0 .\right.
\end{aligned}
$$


Let $\tilde{x}(\gamma)$ denote the solution to (A2). Note that (A2) reduces to (14) when $\gamma=1$, and to (18) when $\gamma=0$, implying that $\tilde{x}(0)=x_{S L}$, and $\tilde{x}(1)=x^{*}$. Finally, differentiating (A5) with respect to $\gamma$ (and recalling that $g^{\prime} \equiv 0$ ) yields

$$
S_{x \gamma}=\int_{0}^{\bar{h}} 2(1-\gamma) \pi(x) \pi^{\prime}(x) g(\cdot)(h-E(h))^{2} f(h) d h<0
$$

given that $\pi^{\prime}<0$. It follows that $\partial \tilde{x}(\gamma) / \partial \gamma<0$, which implies that $\tilde{x}(0)>\tilde{x}(1)$, or $x_{S L}>x^{*}$.

Proof of Proposition 3: Part (a) was demonstrated above for the three rules. The comparison of no liability and negligence when $\lambda<1$ involves evaluating (19) at $\hat{x}(\lambda)$ for no liability and at $x *(\lambda)$ for negligence (assuming compliance). The fact that $x^{*}(\lambda)$ maximizes (19) by definition, however, implies that welfare is higher under negligence.

Proof of Proposition 4: First, we know that when $\lambda=1$, negligence is preferred to strict liability because negligence is efficient and strict liability is not. We also know that welfare under strict liability, given by (17) evaluated $x_{S L}$, or $\left.S_{S L}\left(x_{S L}\right)\right)=W\left(x_{S L}\right)$, is independent of $\lambda$. Thus, all we need to show is that, given compliance with the due standard, negligence is less efficient than strict liability when $\lambda=0$, and that (19) evaluated at $x^{*}(\lambda)$ is increasing in $\lambda$. Together, these facts would establish that $W_{\lambda}\left(x^{*}(\lambda), \lambda\right)$ crosses $S_{S L}\left(x_{S L}\right)$ from below at a single value of $\lambda$ that is strictly between zero and one.

To show that $W_{\lambda}\left(x^{*}(\lambda), \lambda\right)$ is increasing in $\lambda$, note that, since $x^{*}(\lambda)$ maximizes (19), we can use the Envelope Theorem to derive

$$
\frac{\partial W_{\lambda}\left(x^{*}(\lambda), \lambda\right)}{\partial \lambda}=\int_{0}^{\bar{h}} \pi\left(x^{*}(\lambda)\right)^{2} h^{2}(1-\lambda) g(\cdot) f(h) d h>0 .
$$

To show that negligence is less efficient than strict liability at $\lambda=0$, we first define the function 


$$
\widetilde{W}(\lambda)=\int_{0}^{\bar{h}} \int_{c+\tilde{x}(\lambda)+\lambda \pi(\tilde{x}(\lambda)) E(h)}^{\bar{a}}(a-c-\tilde{x}(\lambda)-\lambda \pi(\tilde{x}(\lambda)) h) g(a) f(h) d a d h,
$$

where $\tilde{x}(\lambda)$ is the level of safety that maximizes $\widetilde{W}$. Now observe that when $\lambda=0, \widetilde{W}(0)=$ $W_{\lambda}\left(x^{*}(0), 0\right)$; that is, (A8) coincides with optimized welfare under negligence (given compliance). Also, when $\lambda=1, \widetilde{W}(1)=S_{S L}\left(x_{S L}\right)$; that is, (A8) coincides with the maximized value of consumer surplus under strict liability (which also corresponds to social welfare since misperceptions do not matter). To demonstrate this last claim, note that from (17), the maximized value of consumer surplus under strict liability is

$$
\begin{aligned}
S_{S L}\left(x_{S L}\right) & =\int_{0}^{\bar{h}} \int_{c+x_{S L}+\pi\left(x_{S L}\right) E(h)}^{\bar{a}}\left(a-c-x_{S L}-\pi\left(x_{S L}\right) E(h)\right) g(a) f(h) d a d h \\
& =\int_{0}^{\bar{h}} \int_{c+x_{S L}+\pi\left(x_{S L}\right) E(h)}^{\bar{a}}\left(a-c-x_{S L}-\pi\left(x_{S L}\right) h\right) g(a) f(h) d a d h,
\end{aligned}
$$

where the second line follows by the rules of integration. Finally, again invoking the Envelope Theorem, we have

$$
\begin{aligned}
\frac{\partial \widetilde{W}(\lambda)}{\partial \lambda}= & \pi(\tilde{x})^{2} E(h) g(\cdot) \int_{0}^{\bar{h}}(h-\lambda E(h)) f(h) d h \\
& =\pi(\tilde{x})^{2} E(h)^{2} g(\cdot)(1-\lambda)>0 .
\end{aligned}
$$

Figure 4 shows the resulting relationships among $W_{\lambda}\left(x^{*}(\lambda), \lambda\right)$, realized welfare under negligence; $S_{S L}\left(x_{S L}\right)$, realized welfare under strict liability; $\widetilde{W}(\lambda)$, the function defined in (A8); and $W\left(x^{*}\right)$, welfare at the efficient outcome. The critical value $\lambda^{*}$ is defined by the equation $W_{\lambda}\left(x^{*}(\lambda), \lambda\right)=S_{S L}\left(x_{S L}\right)$, which, by the graph, occurs at a point strictly between zero and one. 


\section{References}

Beard, T., Bankruptcy and Care Choice, 21 Rand Journal of Economics 626-634 (1990).

Coase, R., The Problem of Social Cost, 3 Journal of Law and Economics 1-44 (1960).

Daughety, A. \& J. Reinganum, Economic Analysis of Products Liability: Theory, in J. Arlen, ed., Research Handbook on the Economics of Torts, Edward Elgar (forthcoming).

, Product Safety: Liability, R\&D and Signaling, 85 American Economic Review 1187-1206 (1995).

Epple, D. and A. Raviv, Product Safety: Liability Rules, Market Structure, and Imperfect Information, 68 American Economic Review 80-95 (1978).

Hamada, K. Liability Rules and Income Distribution in Products Liability, 66 American Economic Review 228-234 (1976).

Hay, B. and K. Spier, Manufacturer Liability for Harms Caused by Consumers to Others, 95 American Economic Review 1700-1711 (2005).

Landes, W. and R. Posner, 1985. A Positive Economic Theory of Products Liability, 14 Journal of Legal Studies 535-567 (1985).

Marino, A., Monopoly Liability and Regulation, 54 Southern Economic Journal 913-927 (1988).

Miceli, T., R. Rabon, and K. Segerson, Liability versus Regulation for Controlling ProductRelated Risks, in T. Miceli and M. Baker, eds., Research Handbook on Economic Models of Law, Edward Elgar (forthcoming).

Oi, W., The Economics of Product Safety, 4 Bell Journal of Economics and Management Science 3-28 (1973).

Polinsky, A. M. and W. Rogerson, Products Liability, Consumer Misperceptions, and Market Power, 14 Rand Journal of Economics 581-589 (1983).

Polinsky, A. M. and S. Shavell, The Uneasy Case for Product Liability, 123 Harvard Law Review 1437-1492 (2010).

Shavell, S., The Judgment Proof Problem, 6 International Review of Law and Economics 45-58 (1986).

, Strict Liability versus Negligence, 9 Journal of Legal Studies 463-516 (1980). 
Spence, A. M., Consumer Misperceptions, Product Failure, and Producer Liability, 44 Review of Economic Studies 561-572 (1977).

Spier, K., Product Safety, Buy-Backs, and the Post-Sale Duty to Warn, 27 Journal of Law, Economics and Organization 515-529 (2011). 


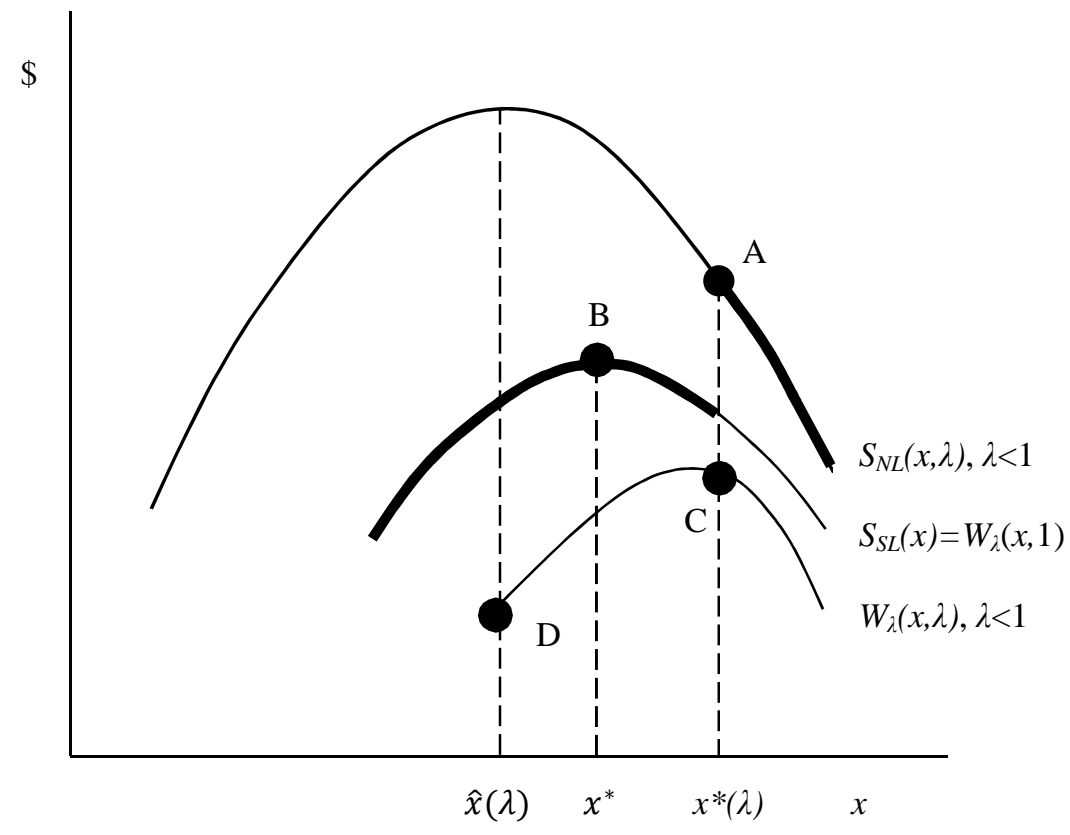

Figure 1. Optimal care choice of firms under negligence with a due standard of $x^{*}(\lambda)$ for the case where $\lambda<1$ and firms choose to comply. 


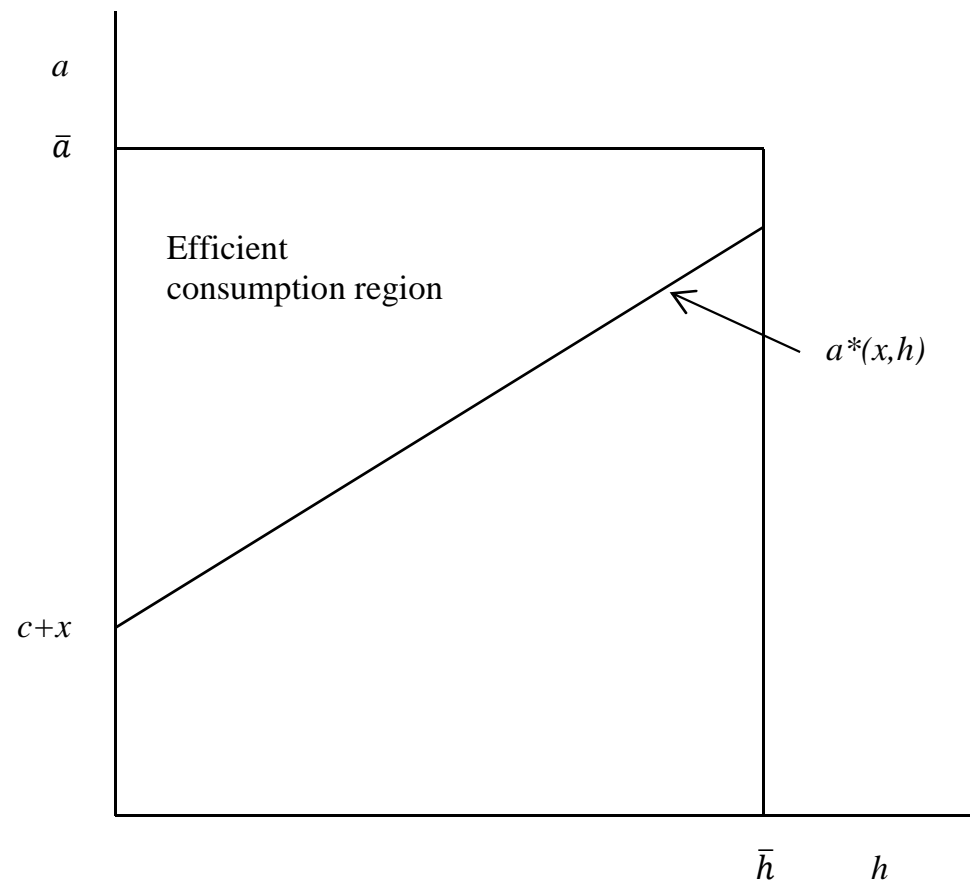

Figure 2. Efficient consumption region when consumers vary in both $a$ and $h$. 


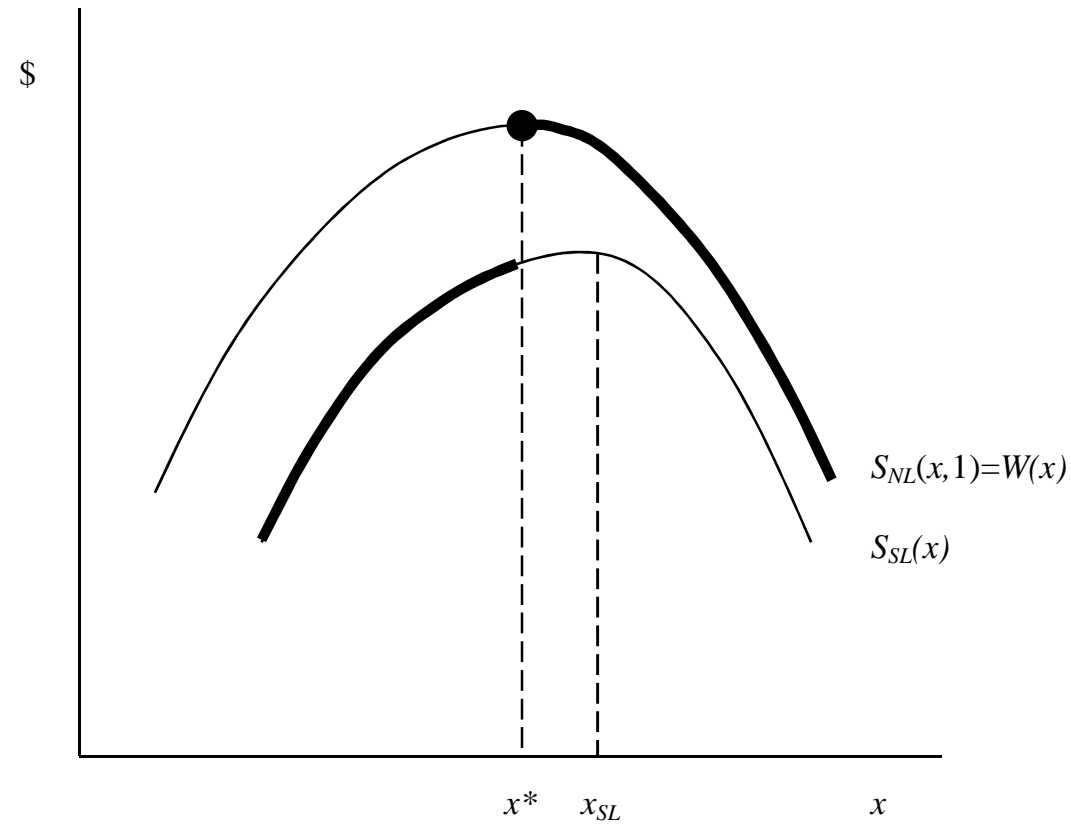

Figure 3. Compliance with the negligence standard when $\lambda=1$. 


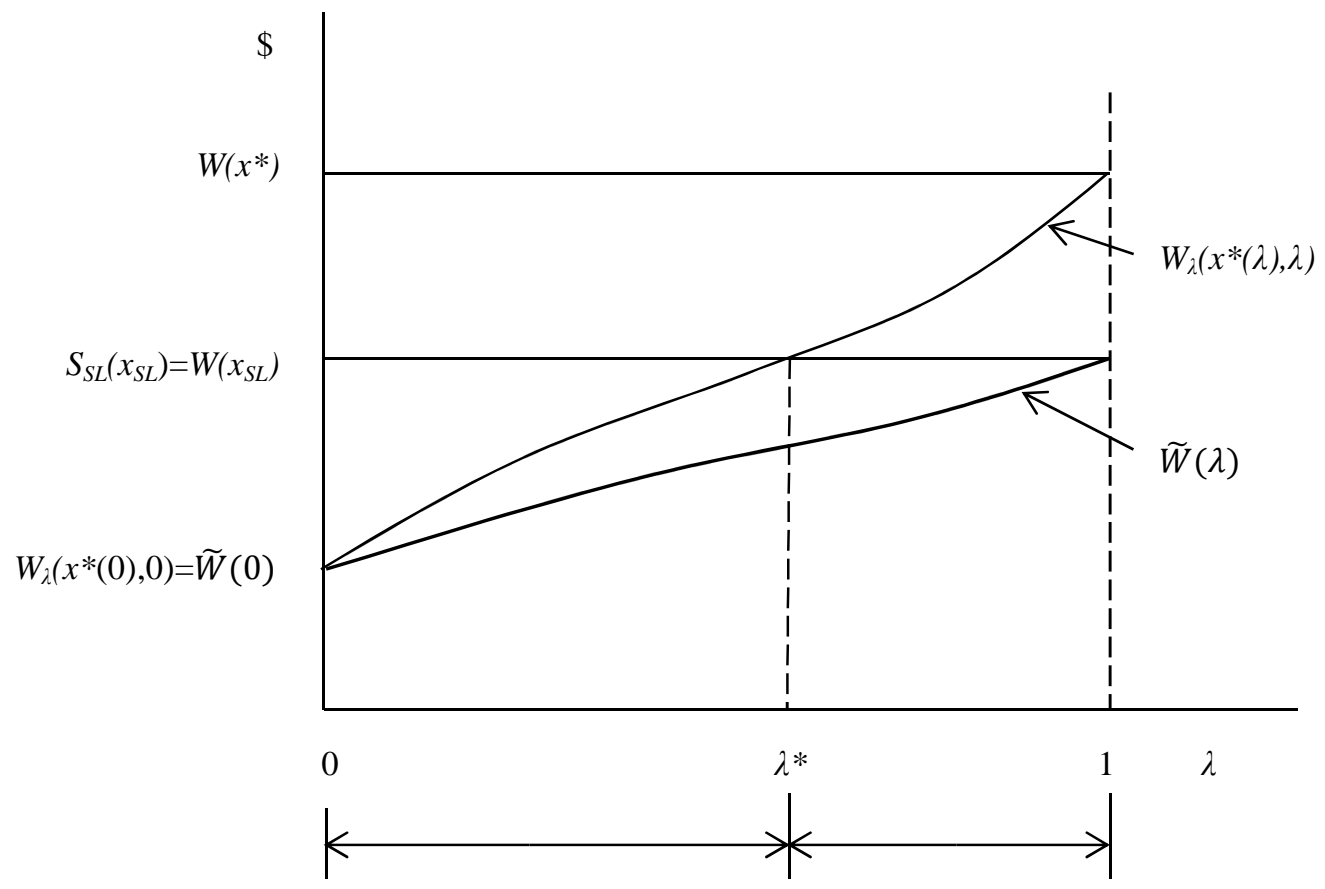

Strict liability optimal Negligence optimal

Figure 4. Threshold for choosing between strict liability and negligence when consumers vary in $h$. 


\section{Consumer perceptions: \\ Accurate $(\lambda=1) \quad$ Inaccurate $(0 \leq \lambda<1)$}

\begin{tabular}{ll|l|l|}
\cline { 3 - 3 } & \multicolumn{1}{|l|}{$\begin{array}{l}\text { No liability, strict } \\
\text { liability, and negligence } \\
\text { all efficient }\end{array}$} & $\begin{array}{l}\text { Only strict liability } \\
\text { efficient; } \\
\text { Negligence preferred to } \\
\text { no liability }\end{array}$ \\
\cline { 3 - 3 } & Varmer & $\begin{array}{l}\text { No liability and } \\
\text { negligence efficient; } \\
\text { strict liability not } \\
\text { efficient }\end{array}$ & $\begin{array}{l}\text { Negligence optimal when } \\
\lambda>\lambda^{*} ; \\
\text { Strict liability optimal } \\
\text { when } \lambda<\lambda^{*}\end{array}$ \\
\hline
\end{tabular}

Table 1: Summary of results. 